\title{
Coronary transfer during arterial switch-the heart of the matter?
}

\author{
W. Hampton Gray, MD, and S. Ram Kumar, MD, PhD, FACS
}

\footnotetext{
From the Division of Cardiac Surgery, Department of Surgery, Keck School of Medicine of the University of Southern California, Los Angeles, Calif; and Heart Institute, Children's Hospital Los Angeles, Los Angeles, Calif.

Disclosures: Authors have nothing to disclose with regard to commercial support.

Received for publication Dec 7, 2017; accepted for publication Dec 18, 2017; available ahead of print Jan 17, 2018.

Address for reprints: S. Ram Kumar, MD, PhD, FACS, Children's Hospital, Los Angeles, 4650 Sunset Blvd, Mailstop \#66, Los Angeles, CA 90027 (E-mail: rsubramanyan@ chla.usc.edu).

J Thorac Cardiovasc Surg 2018;155:e133-4

$0022-5223 / \$ 36.00$

Copyright (c) 2017 by The American Association for Thoracic Surgery

https://doi.org/10.1016/j.jtcvs.2017.12.072
}

During development, progenitor cells that originate from the so-called second heart field populate the arterial pole of the developing heart. After a complex series of interactions between these cells and their counterparts from the cardiac neural crest, the outflow tract is appropriately positioned over the 2 developing ventricles, septated, and connected to the pulmonary and systemic circulations. The coronary arteries on the surface of the heart develop from endothelial cells that migrate out of the coronary sinus and the endocardium. It has been suggested that these coronary arteries ultimately fuse with capillary sprouts that arise from the developing aortic root to establish antegrade coronary perfusion.

The exact molecular mechanisms that govern this final step in coronary development remain to be elucidated. That said, because coronary ostia formation is coupled to outflow tract maturation, proximal coronary anomalies frequently coexist with defects in outflow tract development. Patients with truncus arteriosus commonly have coronary ostial lesions, origin of left anterior descending artery from the right coronary is welldescribed in tetralogy of Fallot - to quote a few examples. The spectrum of associated coronary anomalies has been most extensively documented in the setting of dextro-transposition of great arteries (d-TGA). ${ }^{1,2}$ These anomalies could range from the relatively benign, such as circumflex artery arising from the right coronary artery $(17 \%),^{2}$ to the more complex single coronary ostium or inverted coronary arteries. An intramural coronary origin is seen in $2 \%$ to $5 \%$ of patients with d-TGA, and the most common variant is the left coronary arising from the rightward sinus adjacent to the right coronary artery (Figure 1), coursing behind the posterior valvar commissure, and exiting the aortic wall from leftward sinus.

Surgical approach to repair d-TGA was first successfully attempted in 1960s in the form of physiological correction using atrial baffle techniques popularized by Mustard and Senning. One of the key surgical advances that marked

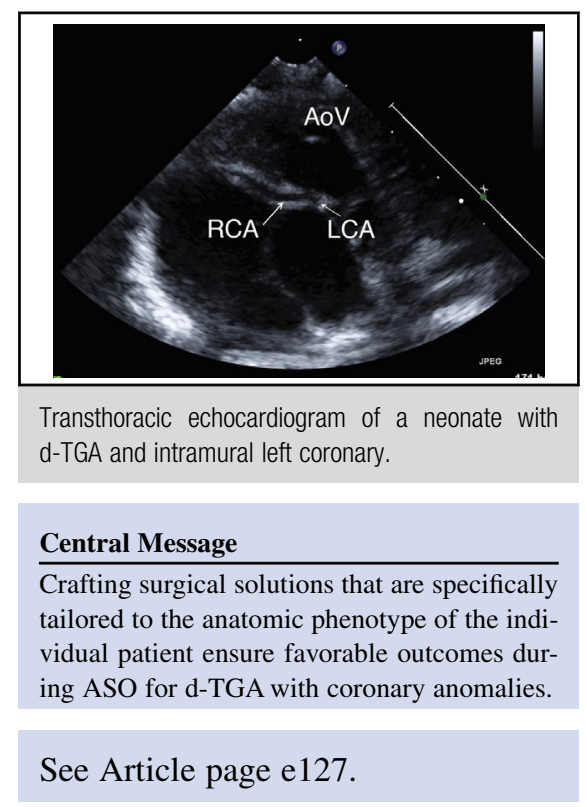

the transition to the now-standard arterial switch operation (ASO) to repair d-TGA was the ability to transfer neonatal coronary ostia from the right to the left ventricular outflow vessel. At least some of the operative mortality associated with ASO in the early era is attributable to technical issues with coronary transfer. ${ }^{4}$ Given its primacy in ASO, a plethora of techniques has been described to achieve successful coronary transfer. Even in the setting of usual coronary pattern, surgeons have used different methods, such as direct implantation of 2 buttons, "trap door" modification, or medial- or lateral-based arterial wall flaps. For every variation in coronary anatomy, multiple alternative surgical approaches have been advocated.

When the coronary artery runs an intramural course, unroofing of the entire intramural segment of the vessel is crucial. After unroofing, direct transfer of the coronary button can usually be achieved. ${ }^{5,6}$ Criticism of this technique centers on the lack of anatomical positioning, which can purportedly lead to tension, stretch, or kinking of the vessel. To circumvent these issues, some have advocated the use of a medial-based neoaortic root flap, pericardial hood or an aorto-pulmonary window to divert neoaortic flow to the coronary ostia.

In this issue of the Journal, Ko and colleagues ${ }^{7}$ elegantly describe a novel "aortic sinus pouch technique" for the transfer of an intramural coronary artery during ASO for 


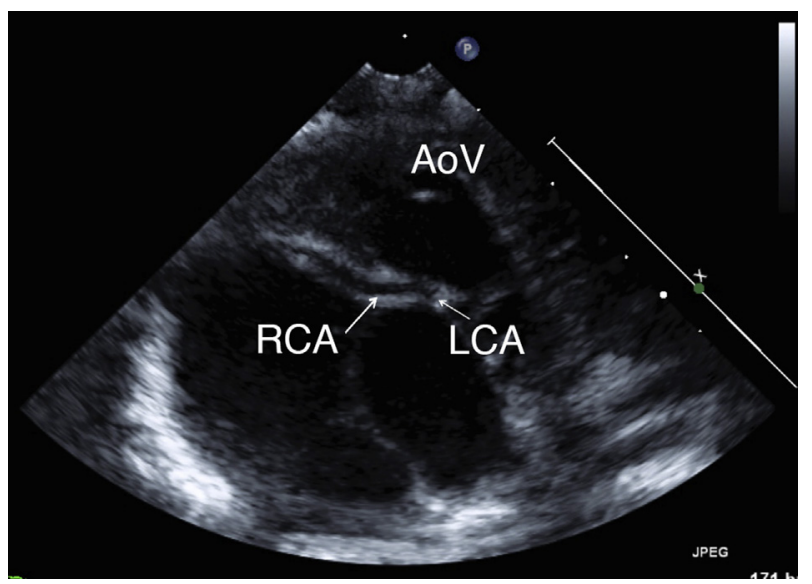

FIGURE 1. Transthoracic echocardiogram of a neonate with transposition of great arteries. The RCA and LCA arise adjacent to one another near one of the commissures of the AoV with a short intramural course of LCA at origin and a subsequent interarterial course. $R C A$, Right coronary artery; $L C A$, left coronary artery; AoV, aortic valve.

d-TGA. After unroofing of the intramural segment of the artery, a pouch that contains both coronary ostia is created from the aortic sinus and is sutured in a double-barrel manner to the neoaortic root. This technique differs from previous reports in that only native aortic tissue is involved in reconstruction of the coronary transfer when direct implantation is not performed. The authors claim that the ostia are in a more normal anatomic position with this technique and the creation of a pouch allows for greater regulation of the length and orientation of the anastomosis. They have previously used this technique to transfer a single coronary ostium and now use it successfully for an intramural coronary course. Although more complex, this technique can be a valuable surgical tool in the setting of high-risk coronary anatomy. There, however, are some concerns with this technique. Because both coronaries now arise from a single pouch, the creation of an adequate-sized pouch that does not distort the coronary origin is crucial. The location of a relatively bulky pouch between the neoaorta and pulmonary artery places it at risk for compression, especially in neonates with pulmonary hypertension.
Whereas it has been widely recognized that anomalous coronary origin increases surgical complexity of ASO, its impact on survival is more controversial. In a retrospective analysis of more than 900 patients, Metton and colleagues ${ }^{3}$ reported a mortality of $28 \%$ for patients with an intramural coronary artery compared with $4 \%$ for those without. In a meta-analysis by Pasquali and colleagues, ${ }^{8}$ patients with an intramural coronary artery had a 6-fold increase in mortality compared with those without an intramural vessel. To the contrary, both Wernovsky and colleagues ${ }^{2}$ and Fricke and colleagues ${ }^{1}$ report no increase in mortality risk from an intramural coronary artery. It is likely that these differences stem from the experience and expertise of the operating surgeon and institution. Since its first report, the surgical approach to ASO has continued to mature. As is the case in a large number of congenital heart defects, the heterogeneity in the anatomic presentation of d-TGA calls for impromptu and ingenious approaches in the operating room. Experienced surgeons are able to craft solutions that are specifically tailored to the anatomic phenotype of the individual patient. Reports such as the one by Ko and colleagues provide us with additional options to better devise such personalized surgical solutions.

\section{References}

1. Fricke TA, d'Udekem Y, Richardson M, Thuys C, Dronavalli M, Ramsay JM, et al. Outcomes of the arterial switch operation for transposition of the great arteries: 25 years of experience. Ann Thorac Surg. 2012;94:139-45.

2. Wernovsky G, Mayer JE, Jonas RA, Hanley FL, Blackstone EH, Kirklin JW, et al. Factors influencing early and late outcome of the arterial switch operation for transposition of the great arteries. J Thoracic Cardiovasc Surg. 1995;109:289-302.

3. Metton O, Calvaruso D, Gaudin R, Mussa S, Raisky O, Bonnet D, et al. Intramural coronary arteries and outcome of neonatal arterial switch operation. Eur J Cardiothorac Surg. 2010;37:1246-53.

4. Trusler GA, Castaneda AR, Rosenthal A, Blackstone EH, Kirklin JW. Current results of management in transposition of the great arteries, with special emphasis on patients with associated ventricular septal defect. J Am Coll Cardiol. 1987;10: 1061-7.

5. Asou T, Karl T, Pawade A, Mee R. Arterial switch: translocation of the intramural coronary artery. Ann Thorac Surg. 1994;57:461-5.

6. Padalino MA, Ohye RG, Devaney EJ, Bove EL. Double intramural coronary arteries in d-transposition of the great arteries. Ann Thorac Surg. 2004;78:2181-3.

7. Ko Y, Nomura K, Kinami H, Kawamura R. Aortic sinus pouch technique for transposition of the great arteries with intramural coronary artery. J Thorac Cardiovasc Surg. 2018;155:e127-32.

8. Pasquali SK, Hasselblad V, Li JS, Kong DF, Sanders SP. Coronary artery pattern and outcome of arterial switch operation for transposition of the great arteries. A meta-analysis. Circulation. 2002;106:2575-80. 